\title{
High performance thin layer chromatography analysis of bioactive components from Curcuma longa; an anti- microbially effective medicinal spice
}

\author{
Kurhekar Jaya Vikas \\ Department of Microbiology, Bharati Vidyapeeth's, Dr. Patangrao Kadam Mahavidyalaya, Sangli, Maharashtra, India
}

Email address:

jaya_kurhekar@rediffmail.com

\section{To cite this article:}

Kurhekar Jaya Vikas. High Performance Thin Layer Chromatography Analysis of Bioactive Components from Curcuma longa; an AntiMicrobially Effective Medicinal Spice. American Journal of BioScience. Special Issue: Pharmacognosy with reference to evaluation of medicinal plants as an alternative therapy. Vol. 3, No. 1-1, 2015, pp. 1-6. doi: 10.11648/j.ajbio.s.2015030101.11

\begin{abstract}
Curcuma longa - haladi, a plant grown as a spice is an entity known to have significant antimicrobial potency. This study was carried out to analyze its bio-active components, with the help of High Performance Thin Layer Chromatography (HPTLC). Anti-microbial effects of $C$. longa were checked using aqueous and acetone extracts, against a few bacterial pathogens causing common infections. The aqueous extract was found effective in inhibiting the growth of eight pathogens (64\% efficiency) while the acetone extract in inhibiting the growth of three pathogens (21\% efficiency). Flavonoid analysis of aqueous extract by HPTLC showed peaks probably corresponding to Coumarins, Triterpenoids, Echinacosides, Eriodictyl, Cichoric acid and Caffeic acid derivatives, responsible for its anti-microbial activities. This natural bio resource may prove to be of significance in the armamentarium of antimicrobial agents.
\end{abstract}

Keywords: Curcuma longa, Antimicrobial Activity, Bio-Active Components, MIC, HPTLC

\section{Introduction}

Indian medicinal plants, constituting a major section of plants in the whole world, are of great importance in the modern scenario, India being one of the richest plant based ethno-medicinal traditions in the world (Baskar and Chezhiyan, 2002). Plants are a source of medicinal agents and raw materials for manufacture of drugs, $1 / 3^{\text {rd }}$ of the pharmaceuticals being of plant origin. WHO currently encourages, recommends and promotes the inclusion of herbal drugs in national health care programs. (Khan and Khanum, 2002). Maharashtra, because of its geographical location and suitable climate, is fit for cultivation of majority of commercially important medicinal crops. Phytomedicines derived from plants have shown great promise in the treatment of intractable infectious diseases including opportunistic AIDS infections. Alkaloids and flavonoids present in many fruits, vegetables have a major role in prevention of several forms of cancers and cardiovascular diseases. Medicinal and Aromatic plants as natural resources are being used up at a high rate and thus have to be maintained and preserved.
Rhizome of Curcuma longa is externally used as a powder, paste, lotion or oil, ointment, decoction. It is known to relieve the symptoms of measles, chicken-pox, URTI and cold (Sathe, 1998)

It is known to be a blood purifier and consumed along with neem fruits, in case of scabies and itching. Worms are traditionally treated with haladi and jaggery. It is used in cases of excessive incontinence, jaundice, cold and cough, poisoning, conjunctivitis, wounds, piles, peri and postdelivery as an anti-septic (Sawant, 1974). Fresh haladi contains curcumin, alkalies, essential (anti-septic) oil, ketone, alcohol, zingiberine and carmin (antacid) (Sathe, 1998) extracts (Sastri, 1952) have been reported as antioxidants of non-enzymatic category, known to exhibit significant antiinflammatory and potential antioxidant activity (Salimath et al, 1986; Chawla et al, 1987). Curcuminoids, a group of phenolic compounds isolated from the roots of $C$. longa, exhibit a variety of beneficial effects on health and prevention of diseases (Joe et al, 2004). A study using RTPCR showed that all three curcuminoids isolated from $C$. longa inhibited multidrug resistance - 1 (MDR-1) gene expression (Limtrakul et al, 2004); Wound healing and detoxifying properties of curcumin have received 
considerable attention (Bone, 1991; Kaushik and Dhiman, 2000; Joe et al, 2004). Its anti-oxidant activity has been proved by Lipid Peroxidation assay and shown to inhibit lipid peroxidation. Scartezzini and Speroni, 2000 ; Ciddi and Kaleab, 2005). It is being used as one of the ingredients of a herbal facial scrub and found comparable with popularly used marketed scrub, showing excellent effects on acne, healing and prevention of pimples, giving fairness, smoother complexion, helping exfoliation (Rawat et al, 2005). Thus, rhizome of $C$. longa has been used as a medicine, spice and coloring agent for thousands of years.

With this perspective, present study was carried out to analyze the bio-active components, in the rhizome of $C$. longa, with the help of High Performance Thin Layer Chromatography.

\section{Materials and Methods}

\section{Preparation of plant extracts:}

For preparation of extracts, fresh rhizomes of $C$. longa have been used.

a) Aqueous extract: Known weight of rhizomes were washed with a known volume of sterile distilled water and crushed in a grinder, till a very fine paste. The material was then filtered through a muslin cloth and Whatman no.40 filter paper. The fine powder obtained on shade drying was used as the sample for investigation (Bambode and Shukla, 1973).

b) Acetone extract: Known weight of rhizomes was washed with a known volume of sterile distilled water and crushed in a grinder using a known amount of acetone. The mixture was refluxed at $60{ }^{\circ} \mathrm{C}$ for one hour. The extract was filtered through muslin cloth and Whatman no. 40 filter paper. Acetone was allowed to evaporate and the powder thus obtained was used as a sample (Shekhawat and Prasada, 1971).

\subsection{Microorganisms used}

Twelve clinical isolates, four Gram positive and eight Gram negative, were used for this study.

Gram positive: Bacillus subtilis, Staphylococcus aureus, Streptococcus species, Micrococcus luteus.

Gram negative: Escherichia coli, Klebsiella pneumoniae, Salmonella typhi, Salmonella paratyphi B, Shigella flexneri, Pseudomonas aeruginosa, Proteus vulgaris and Serratia marsescens.

Detection of anti-microbial activity of the extracts: was carried out by agar-cup diffusion assay method (Finegold and Baron, 1986).

Detection of sensitivity of the isolates to antibiotics: was carried out by disc diffusion assay method (Bauer et al, 1966).

\subsection{Antibiotics Used}

For sensitivity testing, antibiotic octadiscs number OD 042 from Himedia have been used to check the response of the isolates and standard cultures. Most commonly prescribed antibiotics were used; Amikacin, Augmentin, Cephotaxime,
Ciprofloxacin, Cefuroxime, Cefoperazone, Ceftazidime, Gentamicin, Lomefloxacin, Netilmicin, Ofloxacin, Pefloxacin, Nalidixic acid, Nitrofurantoin, Norfloxacin, Doxicycline and Chloramphenicol

\subsection{Qualitative Analysis of the Effective Extracts by HPTLC}

High Performance thin Layer Chromatography (HPTLC) was carried out to verify the presence of constituents in the herbal extract under investigation. Analysis of components was done on the basis of $\mathrm{Rf}$ ie Retention factor values (Gangwar and Kumar, 2006). (Graphs and Tables). Flavonoid analysis was done using;

Instrument: CAMAG TLC Scanner 3 "Scanner3_070408" S/N 070408 (1.14.21),

Stationary phase: TLC Al sheet Silica gel 60 F254 precoated MERCK Cat. No. 1.05554 of size $10 \times 10 \mathrm{~cm}$., Mobile phase: Chloroform : Acetone : Formic acid :: 7.5 : 1.7 : 0.4 .

Sample application volume: $5 \mu \mathrm{l}$. of each sample was applied on precoated layer $10 \mathrm{~mm}$ from the bottom edge, band length $8 \mathrm{~mm}$, distance between the tracks $17.5 \mathrm{~mm}$, distance from the sides $15 \mathrm{~mm}$, Chamber saturation: $0 \mathrm{~min}$, Developing distance: $80 \mathrm{~mm}$, Measurement mode: UV Absorbance / Reflectance, Development chamber: Camag Twin Trough Chamber 10 X $10 \mathrm{~cm}$ with S. S. lid, Developing reagent / Derivatizing agent: Natural products / Polyethylene Glycol No. 28.

Analysis of components was done on the basis of $\mathrm{Rf}$ ie Retention factor values (Gangwar and Kumar, 2006). All the peaks were identified by referring to "Plant drug analysis, A thin layer chromatography, Atlas" by Wagner and Bladt (1996).

\subsection{Statistical Analysis}

The data was analyzed by simple arithmetic means of the diameters of zones of inhibition obtained after repeating the antimicrobial assay three times. The standard error was compared to the control. Statistical analysis of the data was done by applying statistical unpaired t-test. (Mahajan B. K, 1989)

\section{Observations and Results}

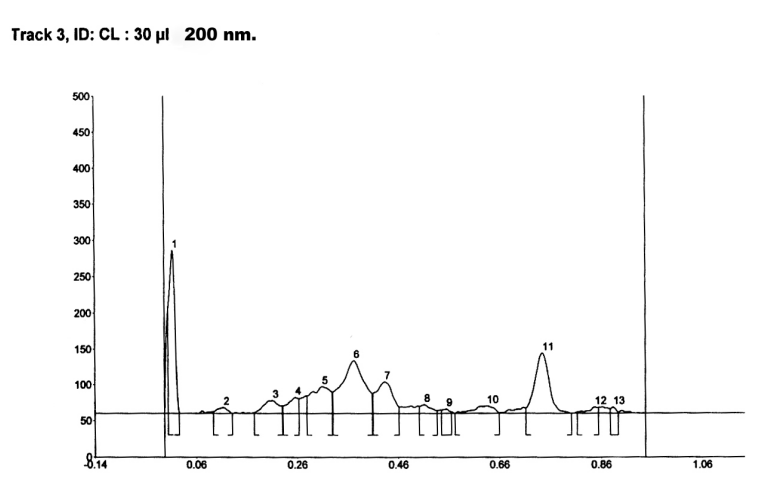

Graph 1. (HPTLC chromatogram of Curcuma longa - $200 \mathrm{~nm}$ ) 
Table I. Effect of extracts of Curcuma longa on common isolates

\begin{tabular}{lll}
\hline Name of the Culture & Aqueous extract & Acetone extract \\
\hline & Mean \pm S.D. & Mean \pm S.D. \\
B.subtilis & $19.33 \pm 1.63$ & - \\
S. aureus & $18.66 \pm 1.36$ & - \\
E. fecalis & $19.66 \pm 1.21$ & $15.66 \pm 1.03^{*}$ \\
Micrococcus luteus & - & $19 \pm 1.41$ \\
E. coli & $16.5 \pm 1.37$ & - \\
K.pneumoniae & - & - \\
S. typhi & $17.83 \pm 1.94$ & - \\
Sparatyphi B & - & - \\
S. flexneri & $16.5 \pm 1.04$ & - \\
$P$. aeruginosa & $15.33 \pm 1.50$ & - \\
P. vulgaris & $19.5 \pm 1.04$ & - \\
S. marsescens & - & $17.5 \pm 1.04$ \\
Total no. of & 8 & 3 \\
orgs. responding & & \\
\hline
\end{tabular}

Key: Values are mean \pm S.E.M. $(\mathrm{n}=3)$, significance Vs control; $* \mathrm{P}<0.05$, significant, $* * \mathrm{P}<0.01$ highly significant, $* * * \mathrm{P}<0.001$, very highly significant,"-" refers to no antibacterial effect of medicinal plant to the mentioned bacterial strain at mentioned dose.

[Zone sizes compared with those of standard antibiotics as referred to in the Zone interpretive chart of standard antibiotics]

Table II. Analysis of Curcuma longa extract by HPTLC (200 nm)

\begin{tabular}{lllll}
\hline $\begin{array}{l}\text { Peak }(200 \\
\text { nm) }\end{array}$ & Rf value & Area & $\begin{array}{l}\text { Relative } \\
\text { conc. \% }\end{array}$ & $\begin{array}{l}\text { Assigned } \\
\text { component }\end{array}$ \\
\hline 2. & 0.11 & 136.5 & 1.25 & Coumarins \\
4. & 0.25 & 391.7 & 3.60 & Triterpenoids \\
9. & 0.55 & 69.9 & 0.64 & Triterpenoids \\
\hline
\end{tabular}

Mobile phase: Toluene : ethyl acetate : formic acid (100\%) $:: 7: 3: 0.2$,

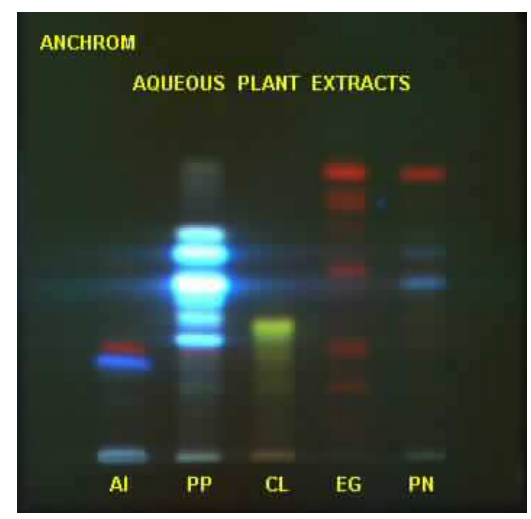

Before derivatisation
Derivatising agent : 5\% Methanolic sulphuric acid.

Table III. Analysis of Curcuma longa extract by HPTLC (366nm)

\begin{tabular}{lllll}
\hline $\begin{array}{l}\text { Peak } \\
(366 \mathbf{~ n m})\end{array}$ & $\begin{array}{l}\text { Rf } \\
\text { value }\end{array}$ & Area & $\begin{array}{l}\text { Relative } \\
\text { conc. } \%\end{array}$ & Assigned component \\
\hline 1. & 0.09 & 606.3 & 2.69 & Echinacoside \\
2. & 0.21 & 2450.3 & 10.86 & Caffeic acid derivative \\
3. & 0.29 & 3340.7 & 14.81 & Eriodictyl \\
4. & 0.37 & 14226.7 & 63.06 & Caffeic acid derivative \\
5. & 0.49 & 803.4 & 3.56 & Caffeic acid derivative \\
6. & 0.71 & 165.2 & 0.73 & Caffeic acid derivative \\
7. & 0.80 & 969.2 & 4.30 & Cichoric acid \\
\hline
\end{tabular}

Mobile phase : Toluene : ethyl acetate : formic acid (100\%) :: $7: 3: 0.2$, Derivatising agent : 5\% Methanolic sulphuric acid.

Track 3, ID: CL $366 \mathbf{~ n m . ~}$

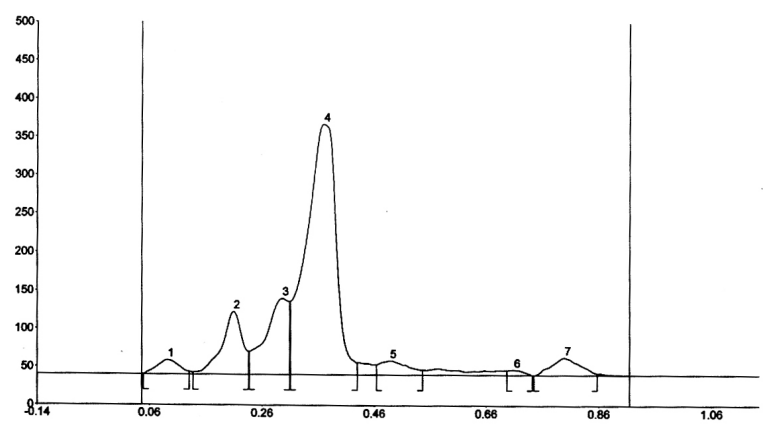

Graph II. HPTLC chromatogram of Curcuma longa (366 nm)

Plate I. HPTLC Chromatograms of aqueous extracts (366 nm)

Key: $\mathrm{CL}=$ Curcuma longa

\section{Discussion}

C. longa is used everyday in Indian kitchens to impart color, flavor and a typical taste to vegetable preparations. It is known to be an antiseptic, anti-inflammatory agent and used in case of emergencies as a dressing. It is used as a gargle in case of throat infections.

In the present study, rhizomes of $C$. longa were extracted in distilled water (17 gm \%) and acetone (44 gm \%). $0.1 \mathrm{ml}$. of each extract was then tested against each isolate, for antimicrobial activity, using bioassay method.

Fourteen lab isolates were used to study the antimicrobial activity of crude aqueous and acetone rhizome extracts of $C$. longa. The aqueous extract was found effective in inhibiting the growth of eight organisms. Gram positive strains were Bacillus subtilis, Staphylococcus aureus, Enterococcus fecalis while Micrococcus luteus was found to be resistant. Of the Gram negative isolates, Escherichia coli, Salmonella 
typhi, Shigella flexneri, Pseudomonas aeruginosa, Proteus vulgaris were found to be susceptible (Table I). The acetone extract was found effective in inhibiting the growth of three organisms. Gram positive strains were Enterococcus fecalis and Micrococcus luteus, Gram negative isolates Serratia marsescens (Table I).

Bacillus subtilis was found to be most sensitive to the aqueous extract while Micrococcus luteus to acetone extract. Pseudomonas aeruginosa was least sensitive to the aqueous extract and Enterococcus fecalis to acetone extract, as concluded from the zone sizes. Comparative efficiencies of aqueous and acetone extracts in inhibiting Enterococcus fecalis were statistically significant. The aqueous extract of $C$. longa showed $64 \%$ efficiency while acetone extract showed $21 \%$ efficiency. Aqueous extract showed more than $50 \%$ efficiency and acetone extract of $C$. longa, less than $50 \%$ efficiency In general, aqueous extract is found better than acetone extract and can be used as a broad spectrum antibiotic to restrict the growth of common pathogens. Aqueous extract of $C$. longa inhibited eight of the fourteen isolates, exhibiting same potency as Gentamicin, Cephotaxime, Netillin, Ofloxacin and Pefloxacin, in its antimicrobial action.

The aqueous extract of $C$. longa extract at $200 \mathrm{~nm}$ showed peaks probably corresponding to coumarins $(1.25 \%)$ and triterpenoids $(3.6 \%, 0.64 \%)$ and at $366 \mathrm{~nm}$, the presence of echinacosides $(2.69 \%)$, eriodictyl $(14.81 \%)$, cichoric acid $(4.3 \%)$ and caffeic acid derivatives $(10.86 \%, 63.06 \%, 3.56 \%$, $0.73 \%$ ).

The clinical bacteriological study of C. longa was effective in case of conjunctivitis (Shrinivas, and Prabhakaran, 1987). The aqueous extract of $C$. longa is effective against pathogens isolated from wounds, Actinomycetal species and two unidentified species. Rhizomes of $C$. longa are considered to have natural antibacterial, anti-inflammatory, antineoplastic and analgesic activities because they contain a number of monoterpenoids, sesquiterpenoids, and curcuminoids (Tang and Eisenbrand, 1992). The extracts of $C$. longa, at concentrations of $5-10 \mathrm{mg} / \mathrm{ml}$, greatly reduced in vitro aflatoxin production by more than $90 \%$, in case of Aspergillus parasiticus (Soni et al, 1992). The antibacterial activity of $C$. longa stem and root extract was reported and was effective against $S$. aureus, $E$. coli and a wide variety of pathogenic bacteria (Chandi et al, 1999). Antimicrobial properties of essential oils of Curcuma longa studied in vitro against $S$. typhi, Kl. pneumoniae, E. coli, S. aureus and B. subtilis, in different concentrations have showed antimicrobial activity against all but maximum activity against $E$. coli (Dubey et al, 2005). All these studies support the investigation carried out.

Banginwar and Tambekar (2003) reported that active principles like tannin, aliphatic ketones, beta-carotenoids, fatty acids, essential oils and phenolic compounds in the extract influence the anti-bacterial activity. Many medicinal plants owe their physiological activities, molecular interactions between alkaloid molecules and chemically defined components of the affected organisms, to their content of alkaloids (Havsteen, 1983). Antioxidant principles from natural resources provide enormous scope in correcting the imbalance between pro-oxidant and antioxidant homeostasis responsible for diseases (Tiwari, 2001). Free radical scavenging activity has been ascribed to natural compounds, flavonoids and polyphenolics (Clark et al, 1985). Flavonoids exert multiple biological effects such as antiflammatory, anti-oxidant, anti-allergic, anti-viral and antimalignancy chemotherapy (Havsteen, 1983). Flavonoids, phenolic compounds are present to a great extent in many fruits and vegetables and have a major role in prevention of several forms of cancer, cardiovascular diseases, cytotoxicity of LDL and are hydrogen donating free radicals with essentially the presence of free hydroxyl Groups and catechol moiety (Shetgiri and D'Mello, 2003). Tannins and alkaloids, plant secondary metabolites, are known to possess antimicrobial activity (Cowan, 1999). Flavonoids and alkaloids have been found to be responsible for antimicrobial activity. Quercitin, Rutin are flavonols (Jadhav and Kharya, 2005) showing very good free radical scavenging activity, flavon-3ols like Catechin too reduce free radicals (Shetgiri and D'Mello, 2003). Components detected in C. longa by HPTLC have also been reported as very active molecules. Eriodictyol may be a good prototype for the development of more effective and/or more potent agents for the treatment of pain (Mateus et al, 2013). The coumarins are of great interest due to their pharmacological properties. In particular, their physiological, bacteriostatic and anti-tumor activity makes these compounds attractive and novel therapeutic agents (Jain and Joshi, 2012) Six new triterpenoids (1-6) were isolated from a Penares sp. sponge collected from Vietnamese waters. Triterpenoid 6 was cytotoxic against human leukemia HL-60 cells $\left(\mathrm{IC}_{50}=9.7 \mu \mathrm{M}\right)$ (Kolesnikova et al, 2013). Echinacoside is one of the major active phenyl ethanoid glycosides in famous traditional Chinese medicine, with various bioactivities, such as antioxidation, neuroprotection, and hepatoprotection (Cunqin Jia et al, 2008). Chicoric acid properties have been reported to include anti-cancer, anti-obesity, antiviral, and anti-diabetic (King and Robinson, 1998; Pluymers et al., 2000; Charvat et al., 2006; Queffelec et al., 2008; Tousch et al., 2008; Tsai et al., 2012; Azay-Milhau et al., 2013; Xiao et al., 2013). Chicoric acid and its analogs have been claimed to possess antiHuman Immunodeficiency Virus (HIV) activity due to its involvement in HIV integrase inhibition, which could perhaps hinder HIV strain replication (King and Robinson, 1998; Charvat et al., 2006; Queffelec et al., 2008). Caffeic acid and some of its derivatives such as caffeic acid phenetyl ester (CAPE) and octyl caffeate are potent antioxidants which present important anti-inflammatory actions. Caffeic acid derivatives exert in vitro and in vivo anti-inflammatory actions (da Cunha FM et al, 2004). Looking at the efficacy of the $C$. longa extracts in inhibiting common pathogens and it being the store house of active components, known to have multiple health benefits, it can be concluded that $C$. longa may be included as an effective antimicrobial agent in the armamentarium of natural agents. If this natural medicinal 
resource is managed efficiently with reference to its protection, conservation, cultivation and propagation, it will continue to prove beneficial to mankind.

\section{References}

[1] Azay-Milhau J., Ferrare K., Leroy J., Aubaterre J., Tournier M., Lajoix A., et al. (2013). Antihyperglycemic effect of a natural chicoric acid extract of chicory (Cichorium intybus L.) a comparative in vitro study with the effects of caffeic and ferulic acids. J. Ethnopharmacol. 150, 755-760

[2] Bambode TS, Shukla VN, (1973). Antifungal Properties of Certain Plant Extracts Against Some Fungi, P.K.V. Res. J., 2, $1-8$.

[3] Baskar RG, Chezhiyan N, (2002). Strength and Wealth of Therapeutic Medicinal Plants in India - Role of Biotechnology in Medicinal and Aromatic Plants, Special Volume on Diseases, Ukaaz Publication, Hyderabad, VI, 149.

[4] Bauer AW, Kirby WM, Sherris JC, Turek M, (1966). Antibiotic Sensitivity Testing by a Standardized Single Disc Method, Am. J. Clin. Pathol, 45, 493.

[5] Bone K, (1991). Turmeric - The spice of life? Br. J. Phytotherapy, 2, 51-60.

[6] Chandi CR, Dash SK, Mishra R., Azeemoddin G., (1999). ibid, 36(2), 133.

[7] Charvat T. T., Lee D. J., Robinson W. E., Chamberlin A. R. (2006). Design, synthesis, and biological evaluation of chicoric acid analogs as inhibitors of HIV-1 integrase. Bioorg. Med. Chem. 14, 4552-4567.

[8] Chawla AS, Handa SS, Sharma AK, Kalik BS, (1987). Plant anti-inflammatory agents, J. Sci. Industri. Res., 46, 214-223.

[9] Ciddi V, Kaleab A, (2005). Anti-oxidants of plant origin, Indian J. Nat. Prod., 21 (4), 3.

[10] Cunqin J, Haiming S, Wei J, Ke Z, Yong J, Mingbo Z, and Pengfei T, (12/2008). Metabolism of Echinacoside, a Good Antioxidant, in Rats: Isolation and Identification of Its Biliary Metabolites, Drug metabolism and disposition 37 (2), 431-8.

[11] da Cunha FM, Duma D, Assreuy J, Buzzi FC, Niero R, Campos MM, Calixto JB (2004). Caffeic acid derivatives: in vitro and in vivo anti-inflammatory properties. Free Radic Res., 38 (11), 1241-53.

[12] Dubey RC, Rana A, Shukla RK, (2005). Antibacterial activity of essential oils of some medicinal plants against certain certain human pathogens, Indian Drugs, 42(7): 443-446.

[13] Finegold SM, Baron EJ, (1986). Diagnostic Microbiology, $7^{\text {th }}$ Edn., The C.V. Mosby Company, St. Louis, 176.

[14] Gangwar P, Kumar M, (2006). Antibacterial Properties and Phytochemical Analysis of the Essential Oil and Aqueous Extract of Mentha spicata (Spearmint), Ind. Drugs, 43: 55-58.

[15] Harbourne JB, (1973). Phytochemical Methods, Toppan Company Ltd., Tokyo, Japan, 1-6.

[16] Jain P. K. and Joshi H., (2012). Coumarin: Chemical and Pharmacological Profile, Journal of Applied Pharmaceutical Science, 02 (06); 236-240.
[17] Joe B, Vijaykumar M, Lokesh BR, (2004). Biological properties of curcumin-cellular and molecular mechanisms of action. Crit. Rev. Food Sci. Nutr., 44: 97-111.

[18] Kaushik P, Dhiman AK, (2000). Medicinal Plants and Raw Drugs of India, Singh B., Singh M.P., Dehradun, XII: 623.

[19] Khan IA, Khanum A, (2002). Role of Biotechnology in Medicinal and Aromatic Plants, Special Volume on Diseases, Ukaaz Publications, Hyderabad, VI: 4-6.

[20] Khandelwal KR, Practical Pharmacognosy, (2001). $8^{\text {th }}$ edn., Nirali publication, 149-153.

[21] King P. J., Robinson W. E., Jr. (1998). Resistance to the antihuman immunodeficiency virus type 1 compound L-chicoric acid results from a single mutation at amino acid 140 of integrase. J. Virol. 72, 8420-8424.

[22] Kokate CK, Purohit AP, Gokhale SB, (2001). Pharmacognosy, $1^{7 \text { th }}$ edition, Nirali Prakashan, Pune, 197, 445.

[23] Limtrakul PS, Anuchapreeda, Buddhasukh D, (2004). Modulation of human multidrugresistance MDR-1 gene by natural curcuminoids. BMC Cancer, 4: 13.

[24] Mahajan BK, (1989). Methods in Biostatistics, $4^{\text {th }}$ edition, Jaypee brothers, New Delhi, 140-141.

[25] Mateus FR, Gabriela T, Cristiani I, Banderó W, Jonatas ZK, Ana P de O, Jardel GI, Ricardo BZ, Luiz FFR, Margareth LA, Marcus VO, Juliano F, (2013). Biochemical Pharmacology, Volume 81, Issue 4, Eriodictyol: A flavonoid antagonist of the TRPV1 receptor with antioxidant activity, Front Chem. 1: 40.

[26] Pluymers W., Neamati N., Pannecouque C., Fikkert V., Marchand C., Burke T. R., Jr., et al. (2000). Viral entry as the primary target for the anti-HIV activity of chicoric acid and its tetra-acetyl esters. Mol. Pharmacol. 58, 641-648.

[27] Queffelec C., Bailly F., Mbemba G., Mouscadet J., Hayes S., Debyser Z., et al. (2008). Synthesis and antiviral properties of some polyphenols related to Salvia genus. Bioorg. Med. Chem. Lett. 18, 4736-4740.

[28] Rawat S, Nijwante S, Jaiswal L, Laila F, (2005). Preparation and evaluation of a new facial scrub as a skin cosmetic, Indian J. Nat. Prod., 21(4): 31.

[29] Salimath BP, Sundaresh CS, Srinivas L, (1986). Dietary components inhibit peroxidation in erythrocyte membrane Nutr. Res., 1171-1178.

[30] Sastri BN, (1952). The wealth of India, Raw materials, CSIR, New Delhi, III: 168.

[31] Sathe AV, (1998). Gharguti Aushadhe, $15^{\text {th }}$ edn., Ganesh printers Pune, 336-337.

[32] Sawant SY, (1974). Maharashtratil Divya Vanaushadhi, Continental publications, Pune, 273.

[33] Scartezzini P, Speroni E, (2000). J.Ethnopharmacol., 71(1-2), 23.

[34] Shekhawat PS, Prasada R, (1971). Antifungal Properties of some Plant Extracts, Ind. Phytopath, 24: 800-802.

[35] Shrinivas, Prabhakaran KUS, (1987). Clinical bacteriological study of C.longa on conjunctivitis, Antiseptic, 84: 166-168.

[36] Singh A, (1977). Practical Plant Physiology, Kalyani Publishers, New Delhi- Ludhiana, 94-116. 
[37] Soni KB, Rajan A, Kuttan R, (1992). Reversal of aflatoxin induced liver damage by turmeric and curcumin, Cancer Lett..

[38] Kolesnikova SA, Lyakhova EG, Kalinovsky AI, Pushilin MA, Afiyatullov SS, Yurchenko EA, Dyshlovoy SA, Minh CV, and Stonik VA, (2013). Isolation, Structures, and Biological Activities of Triterpenoids from a Penares sp. Marine Sponge, J. Nat. Prod, J. Nat. Prod., 76 (9), 1746-1752.

[39] Tang W, Eisenbrand G, (1992). Chinese Drugs of Plant Origin, Springer-Verlag: Berlin and Heidelberg, Germany, 401-415.

[40] Tousch D., Lajoix A., Hosy E., Azay-Milhau J., Ferrare K., Jahannault C., et al. (2008). Chicoric acid, a new compound able to enhance insulin release and glucose uptake. Biochem. Biophys. Res. Comm. 377, 131-135.
[41] Tsai Y., Chiu C., Chen J., Chan K., Lin S. (2012). Cytotoxic effects of Echinacea purpurea flower extracts and cichoric acid on human colon cancer cells through induction of apoptosis. J. Ethnopharm. 143, 914-919.

[42] Vogel AI, (1966), Elementary Practical Organic Chemistry, Part 2, Qualitative Organic Analysis, ${ }^{\text {2nd }}$ Edn., CBS Publishers and Distributors, Delhi, 90-91, 163-164.

[43] Xiao H., Wang J., Yuan L., Xiao C., Wang Y., Liu X. (2013). Chicoric acid induces apoptosis in 3T3-L1 preadipocytes through ROS-mediated PI3K/Akt and MAPK signaling pathways. J. Agric. Food Chem., 61, 1509-1520. 